\title{
AVALIAÇÃO MICROBIOLÓGICA E PARASITOLÓGICA DE PRODUTOS MINIMAMENTE PROCESSADOS NO MUNICÍPIO DE PRESIDENTE PRUDENTE - SP
}

Marcela de Andrade Bernal Fagiani, Karen Natsumi Togawa, Telma Reginato Martins, Nair Toshiko Tashima, Fernanda Leli Dillio, Pedro Henrique Nahas Chagas, Maria Aparecida da Silva

Universidade do Oeste Paulista - UNOESTE, Presidente Prudente, SP. E-mail: $\underline{\text { masilva@unoeste.br }}$

\section{RESUMO}

Há uma maior preocupação da população em relação à saúde, visando melhorá-la por meio de uma alimentação equilibrada e variada incluindo frutas e hortaliças. Para facilitar as preparações é possível optar pelos alimentos minimamente processados, que podem afetar a saúde se forem mal manipulados. $O$ objetivo desse estudo foi desenvolver uma avaliação parasitológica e microbiológica dos minimamente processados que podem ser consumidos sem cozimento no município de Presidente Prudente. Os microrganismos pesquisados foram Salmonella spp., coliformes a $35^{\circ} \mathrm{C}$, coliformes a $45^{\circ} \mathrm{C} / \mathrm{g}$ e Escherichia coli $e$ bolores e leveduras. Foram utilizados os métodos de Faust e Hoffman, mediante análise do sedimento obtido após lavagem das amostras em solução de detergente neutro $(0,5 \%)$ recém-preparada em solução fisiológica a $0,9 \%$. Foram encontrados a partir das análises nos alimentos minimamente processados, coliformes fecais, totais, bolores e leveduras.

Palavras-chave: análise de alimentos, higiene dos alimentos, produtos vegetais, doenças transmitidas por alimentos.

\section{MICROBIOLOGICAL AND PARASITOLOGICAL EVALUATION OF MINIMALLY PROCESSED PRODUCTS IN THE COUNTY OF PRESIDENTE PRUDENTE - SP}

\begin{abstract}
Currently, there is a great concern of the population regarding health, seeking to improve it through a balanced and varied diet including fruits and vegetables. To facilitate the preparation it is possible to choose minimally processed foods, which can affect health if they are poorly handled. The objective of this study was to develop a parasitological and microbiological evaluation of the minimally processed ones that can be consumed without cooking in the municipality of Presidente Prudente. The microorganisms studied were Salmonella spp., coliforms at $35^{\circ} \mathrm{C}$, coliforms at $45^{\circ} \mathrm{C} / \mathrm{g}$ and Escherichia coli and molds and yeasts. Faust and Hoffman methods were used by analyzing the sediment obtained after washing the samples in neutral detergent solution $(0.5 \%)$, freshly prepared in $0.9 \%$ physiological solution. Were found from the analyzes in minimally processed foods, fecal coliforms, totals, molds and yeasts.
\end{abstract}

Keywords: food analysis, food hygiene, vegetable products, foodborne diseases.

\section{INTRODUÇÃO}

O ritmo de vida faz com que os consumidores tenham cada vez menos tempo para se dedicarem à alimentação, preferindo alimentos que sejam saudáveis e, simultaneamente, de preparação fácil e rápida. $\mathrm{A}$ população vem modificando seus hábitos alimentares e, cada vez mais, torna-se clara a relação entre dieta e prevenção de doenças'. Alguns dos requisitos buscados pelos consumidores no momento da escolha dos alimentos são que os mesmos favoreçam preparo rápido, refeições prontas para comer e facilidade de transporte, ou seja, produtos com reduzido tempo de preparação².

Há cada vez mais a preferência por frutas e vegetais frescos, pré-preparados, sendo os mais procurados como itens de conveniência, perante a praticidade decorrente desse produto, pois para ser comercializados, são submetidos ao prépreparo, sendo lavados, descascados, cortados e empacotados ${ }^{1}$. A qualidade microbiológica dos 
alimentos minimamente processados está associada à presença de microrganismos deteriorantes o que poderá influenciar nas alterações sensoriais do produto durante sua venda ${ }^{3}$.

Em razão de sua alta perecibilidade, os produtos minimamente processados são comercializados, de maneira geral, no período de no máximo, 5 dias $^{4}$.

Mesmo com todos os cuidados que são tomados, ainda existem alimentos contaminados que ameaçam a saúde dos consumidores. A atividade dos microorganismos em produtos minimamente processados podem sofrer influências de acordo metabolismo do tecido de cada planta, pela atmosfera modificada, pela permeabilidade do filme de embalagem e pela temperatura de estocagem ${ }^{5}$. Alimentos de origem vegetal podem ser colonizados principalmente por saprófilos e agentes biológicos deteriorantes das plantas ${ }^{6}$. 0 manuseio inadequado e os equipamentos não higienizados corretamente contribuem para o aumento da população de microrganismos nas hortaliças, causando maiores riscos de ação de patógenos e deterioradores nesses produtos ${ }^{5}$.

Geralmente, a Vigilância Sanitária não é notificada por conta de que os sintomas logo desaparecerem. Em pesquisa realizada no município de Chapecó (SC), com relação aos microrganismos envolvidos, Salmonella spp. foi o mais encontrado nas análises, representando o agente etiológico de $54,0 \%$ dos surtos, seguido de Staphylococus aureus com $13,1 \%$ e Bacillus cereus com $9,8 \%{ }^{7}$.

A Resolução RDC $\mathrm{N}^{0} 12$, de 2 de janeiro de 2001, do Ministério da Saúde ${ }^{3}$, estabelece os padrões microbiológicos sanitários para alimentos, não existindo padrões específicos para os produtos minimamente processados. Estes podem ser inseridos no grupo de alimentos designados como: hortaliças, legumes e similares, incluindo cogumelos (fungos comestíveis) frescos, in natura, preparados (descascadas ou selecionadas ou fracionadas) sanificadas, refrigeradas ou congeladas, para consumo direto, com exceção de cogumelos, cuja tolerância máxima para amostra indicativa é de $5 \times 10^{2}$ NMP.g. ${ }^{-1}$ ou UFC. $g^{-1}$ de coliformes a $45^{\circ} \mathrm{C}$ e ausência de Salmonella spp. em $25 \mathrm{~g}$.

A manutenção das características dos produtos minimamente processados é um desafio, uma vez que, logo após a colheita, reações químicas e físicas passam a ocorrer e podem influenciar na qualidade e aumentar a vulnerabilidade aos microrganismos destruidores, diminuindo assim a vida útil. Quando frutas e hortaliças são submetidas a processos que levam a uma alteração na sua estrutura natural, tais como: descascamento, corte, trituração e injúrias diversas, o produto sofre modificações, podendo estas ser decorrentes da ação de enzimas naturalmente presentes que entram em contato com diversos substratos, que associada ao de oxigênio podem desenvolver no produto uma coloração escura'.

As técnicas para embalar alimentos tiveram uma evolução significativa nas últimas décadas, de acordo com a necessidade de manter o produto seguro, com o objetivo de aumentar seu tempo de vida útil, procurar uma melhor relação custo-benefício, responder a questões ambientais e também às exigências dos consumidores ${ }^{2}$.

Existem diversos alimentos que podem ser consumidos crus, como é o caso do cheiro verde que é um condimento, geralmente utilizado cru, e consiste em salsinha e cebolinha. É muito utilizado para finalização de pratos como decoração ou tempero, e também no preparo de maioneses em lanches. Como o cheiro verde pode ser usado para fazer maionese, conhecida como "molho verde" nos lanches, vale lembrar que nem todos os estabelecimentos utilizam maionese industrializada. O tabule é outro alimento que é consumido cru, de origem árabe, basicamente feito com triguilho (trigo para quibe), tomate, cebola, salsa, hortelã, entre outros temperos, consumido por cima das folhas de alface. A alface é um alimento sempre consumido cru e muito apreciado pela população brasileira, além de acompanhar diversos tipos de preparações e possuir alto teor de fibras, é um alimento regulador contendo vitaminas e minerais. A beterraba quando ralada é consumida crua e traz benefícios à saúde, promove formação de células vermelhas do sangue, é fonte de ácido málico e contém grande quantidade de açúcar. A couve é rica em vitamina A, B6, C, K e minerais como Cálcio e Ferro, possui ação antihelmíntica, laxativa, e por ser pobre em calorias é muito presente em dietas de pessoas que objetivam o emagrecimento, ingeridas na forma de suco e saladas, portanto é consumida crua na maioria das preparações.

O Objetivo desse trabalho foi avaliar por meio de análises microbiológicas e parasitológicas, alimentos minimamente 
processados geralmente consumidos crus tais como: cheiro verde, preparado para tabule, alface, beterraba e couve. A avaliação dos aspectos higiênico-sanitários destes alimentos foi comparada com as exigências legais.

\section{METODOLOGIA}

Foram adquiridos no comércio local, amostras de cheiro verde, preparado para tabule, alface, beterraba e couve minimamente processados, em triplicata de cada produto, totalizando 15 amostras. Estes foram acondicionados em caixa térmica para o transporte até o laboratório. Em seguida foram realizadas as análises microbiológicas e posteriormente a análise parasitológica.

Análise Microbiológica

Os microrganismos pesquisados foram enterobactérias, como Salmonella spp. $e$ Escherichia coli. As análises de Coliformes a $35^{\circ} \mathrm{C}$ e de Coliformes a $45^{\circ} \mathrm{C} / \mathrm{g}$ e Escherichia coli, Bolores e Leveduras e Salmonella spp. / 25g, foram realizadas segundo Silva et al. ${ }^{8}$.

Tabela 1. Beterraba minimamente processada.

\begin{tabular}{ccccc}
\hline Beterraba & $\begin{array}{c}\text { Salmonella spp. } \\
\text { (em 25g) }\end{array}$ & $\begin{array}{c}\text { Coliformes Fecais } \\
\text { (NMP/g) }\end{array}$ & $\begin{array}{c}\text { Coliformes Totais } \\
\text { (NMP/g) }\end{array}$ & $\begin{array}{c}\text { Bolores e Leveduras } \\
\text { UFC/g }\end{array}$ \\
\hline A1 & Ausência & $<3$ & 4 & $92,5 \times 10^{3}$ \\
A2 & Ausência & $<3$ & $<3$ & $117,5 \times 10^{3}$ \\
A3 & Ausência & $<3$ & 28 & $128,5 \times 10^{3}$ \\
\hline
\end{tabular}

No cheiro Verde Minimamente

Coliformes Fecais, porém houve presença de Bolores e Leveduras e Coliformes Totais.
Análise Parasitológica

Foram utilizados os métodos de Faust e Hoffman segundo Vallada ${ }^{9}$ mediante análise do sedimento obtido após lavagem das amostras em solução de detergente neutro $(0,5 \%)$ recémpreparada em solução fisiológica a $0,9 \%$.

\section{RESULTADOS}

Aspecto Organolépticos

As Amostras dos produtos minimamente processados foram acondicionados em caixa térmica para o transporte até o laboratório, porém o Alface minimamente processado, estava com as bordas bem escuras, com cheiro forte e a Beterraba estava muito ressecada.

Análise Microbiológica

$\mathrm{Na}$ Beterraba minimamente processada, houve ausência de Salmonella spp. e Coliformes Fecais, porém houve presença de Bolores e Leveduras e Coliformes Totais.

Processado, houve ausência de Salmonella spp. e

Tabela 2. Cheiro verde minimamente processado.

\begin{tabular}{ccccc}
\hline Cheiro Verde & $\begin{array}{c}\text { Salmonella spp. } \\
\text { (em 25g) }\end{array}$ & $\begin{array}{c}\text { Coliformes Fecais } \\
\text { (NMP/g) }\end{array}$ & $\begin{array}{c}\text { Coliformes Totais } \\
\text { (NMP/g) }\end{array}$ & $\begin{array}{c}\text { Bolores e Leveduras } \\
\text { UFC/g }\end{array}$ \\
\hline B1 & Ausência & $<3$ & $<3$ & $33,5 \times 10^{3}$ \\
B2 & Ausência & $<3$ & 11 & $37,5 \times 10^{3}$ \\
B3 & Ausência & $<3$ & 1000 & $107,5 \times 10^{3}$ \\
\hline
\end{tabular}

$\mathrm{Na}$ Alface Minimamente Processado, houve ausência de Salmonella spp. e Coliformes
Fecais, porém houve presença de Bolores e Leveduras e Coliformes Totais.

Tabela 3. Alface minimamente processado.

\begin{tabular}{ccccc}
\hline Alface & $\begin{array}{c}\text { Salmonella spp. } \\
\text { (em 25g) }\end{array}$ & $\begin{array}{c}\text { Coliformes Fecais } \\
\text { (NMP/g) }\end{array}$ & $\begin{array}{c}\text { Coliformes Totais } \\
\text { (NMP/g) }\end{array}$ & $\begin{array}{c}\text { Bolores e Leveduras } \\
\text { UFC/g }\end{array}$ \\
\hline C1 & Ausência & $<3,0$ & $>1.100$ & $55,3 \times 10^{3}$ \\
C2 & Ausência & 3,6 & $>1.100$ & $48 \times 10^{3}$ \\
C3 & Ausência & 3,0 & $>1.100$ & $65 \times 10^{3}$ \\
\hline
\end{tabular}


Na Couve Minimamente Processado, houve ausência de Salmonella spp., porém houve presença de Coliformes Fecais, de Bolores e Leveduras e Coliformes Totais.

Tabela 4. Couve minimamente processado.

\begin{tabular}{ccccc}
\hline Couve & $\begin{array}{c}\text { Salmonella spp. } \\
\text { (em 25g) }\end{array}$ & $\begin{array}{c}\text { Coliformes Fecais } \\
\text { (NMP/g) }\end{array}$ & $\begin{array}{c}\text { Coliformes Totais } \\
\text { (NMP/g) }\end{array}$ & $\begin{array}{c}\text { Bolores e Leveduras } \\
\text { UFC/g }\end{array}$ \\
\hline D1 & Ausência & $<3,0$ & $>1.100$ & $27,5 \times 10^{3}$ \\
D2 & Ausência & $<3,0$ & 1.100 & $58,5 \times 10^{3}$ \\
D3 & Ausência & $<3,0$ & $>1.100$ & $13 \times 10^{3}$ \\
\hline
\end{tabular}

No Tabule Minimamente Processado, houve ausência de Salmonella spp., porém houve presença de Coliformes Fecais, Bolores e Leveduras e Coliformes Totais.

Tabela 5. Tabule minimamente processado.

\begin{tabular}{ccccc}
\hline Tabule & $\begin{array}{c}\text { Salmonella spp. } \\
\text { (em 25g) }\end{array}$ & $\begin{array}{c}\text { Coliformes Fecais } \\
\text { (NMP/g) }\end{array}$ & $\begin{array}{c}\text { Coliformes Totais } \\
\text { (NMP/g) }\end{array}$ & $\begin{array}{c}\text { Bolores e Leveduras } \\
\text { UFC/g }\end{array}$ \\
\hline E1 & Ausência & 3,6 & $>1.100$ & $81,5 \times 10^{3}$ \\
E2 & Ausência & $<3,0$ & $>1.100$ & $258 \times 10^{3}$ \\
E3 & Ausência & $<3,0$ & $>1.100$ & $65,5 \times 10^{3}$ \\
\hline
\end{tabular}

\section{DISCUSSÃO}

analisar microbiologicamente e
parasitologicamente alguns tipos de alimentos minimamente processados, comercializados no município de Presidente Prudente, visto que, segundo Smanioto et al. ${ }^{10}$, vem crescendo no mercado a procura por alimentos minimamente processados pela população.

Segundo a Agência Nacional de Vigilância Sanitária (ANVISA), foram determinadas as quantidades máximas permitidas sobre a presença de microrganismos nos alimentos de origem vegetal, que é de $5 \times 10^{2}$ para coliformes a $45^{\circ} \mathrm{C} / \mathrm{g}$ e ausente para Salmonella spp./ $25 \mathrm{~g}$, no grupo de alimentos frescos, "in natura", preparados (podendo estar descascados, selecionados ou até mesmo, fracionados) estando estes em boas condições sanitárias, podendo estar congelados ou refrigerados ${ }^{11}$. A partir das análises microbiológicas, houve ausência de Salmonella spp. nas amostras utilizadas.

Deve-se ficar atento às condições higiênicas dos alimentos, que segundo Pena et al. ${ }^{12}$, pode ser contaminado por diversos fatores, e tornar-se um veículo para transmissão de doenças, de modo que a detecção e investigação de surtos de doenças transmitidas por alimentos (DTA) é um dos principais desafios para o Sistema único de Saúde (SUS).
Foram encontrados poucos estudos recentes que tratam sobre estes tipos de alimentos, contudo, segundo Santos et al..13, vários autores citam as hortaliças cruas, com ênfase para as alfaces no que diz respeito a alimento veiculador de patógenos em surtos de toxinfecções, devido à presença de Escherichia coli, Salmonella spp., Listeria monocytogenes, não sendo o caso do presente trabalho, onde na análise da alface, foram encontrados com valores relevantes bolores, leveduras e coliformes totais.

Segundo Prado et al. ${ }^{14}$, é de extrema importância para a saúde pública a realização de estudos que contribuam na avaliação das condições higiênico-sanitárias dos alimentos de qualquer grupo alimentar, para que hava a promoção na melhora da qualidade dos alimentos e auxiliar a detecção de falhas no processo de produção, além de prevenção de DTA.

\section{CONCLUSÃO}

Os resultados mostraram que houve presença de Coliformes Fecais, Totais, Bolores e Leveduras nos alimentos minimamente processados, sendo necessário que o fabricante melhore a qualidade da manipulação dos alimentos, seguindo o Manual de Boas Práticas de Fabricação, para garantir alimentos seguros ao consumidor. Não houve presença de Salmonella spp. nos produtos minimamente processados 
analisados, porém em outros estudos com produtos minimamente procesados já foram identificados Salmonella spp. em hortaliças frescas in natura. O consumidor, deve estar atento durante a compra, analizando sempre a validade dos produtos e as condições sensoriais, pois os produtos minimamente processados devem apresentar suas características organolépticas preservadas e razoavelmente livre de defeitos.

\section{CONFLITO DE INTERESSE}

Os autores declaram não haver qualquer potencial de conflito de interesse que possa interferir na imparcialidade deste trabalho científico.

\section{REFERÊNCIAS}

1. Maistro LC. Alface minimamente processada: uma revisão. Rev. Nutr. [Internet]. 2001. [acesso em 2013 Dez 20]; 14 (3): 219-224. DOI: http://dx.doi.org/10.1590/S1415-

\section{8}

2. Santos JS, Oliveira MBPP. Revisão: alimentos frescos minimamente processados embalados em atmosfera modificada. Braz J Food Technol. 2012;15(1):1-14.

3. Pinheiro NM de $S$, Figueiredo EAT de, Figueiredo RW de, Maia GA, Souza PHM. Avaliação da qualidade microbiológica de frutos minimamente processados comercializados em supermercados de fortaleza. Rev Bras Frutic. 2005;27(1):153-6.

4. Verzeletti A, Fontana RC, Sandri IG. Avaliação da vida de prateleira de cenouras minimamente processadas. Alim Nutr. 2010;21(1):87-92.

5. Fantuzzi E, Puschmann R, Vanetti MCD. Microbiota contaminante em repolho minimamente processado. Ciênc Tecnol Aliment. 2004;24(2):207-11. DOI: http://dx.doi.org/10.1590/s0101-

\section{8}

6. Kokkinakis EN, Fragkiadakis GA. HACCP effect on microbiological quality of minimally processed vegetables: a survey in six mass-catering establishments. Int J Food Sci Technol. 2007; 42(1):18-23.

DOI:

http://dx.doi.org/10.1111/i.1365-

\subsubsection{9.x}

7. Marchi DM, Baggio N, Teo CRPA, Busato MA. Ocorrência de surtos de doenças transmitidas por alimentos no município de Chapecó, estado de
Santa Catarina, Brasil, no período de 1995 a 2007. Epidemol Serv Saúde. 2011;20(3):401-7.

8. Silva N, Junqueira VCA, Silveira NFA. Manual de métodos de análise microbiológica de alimentos. 1.ed. São Paulo: Varela; 1997.

9. Silva SRP da, Verdin SEF, Pereira DC, Schatkoski AM, Rott MB, Corção G. Microbiological quality of minimally processed vegetables sold in Porto Alegre, Brazil. Braz J Microbiol. 2007;38(4):594-8. DOI: http://dx.doi.org/10.1590/S151783822007000400003

10. Smanioto TF, Pirolo NJ, Simionato EMRS, Arruda MC de. Qualidade microbiológica de frutas e hortaliças minimamente processadas. Rev Inst Adolfo Lutz. 2009;68(1):150-4.

11. Brasil. Resolução RDC $\mathrm{n}$ - 12 , de 2 de Janeiro de 2001. Aprova o regulamento técnico sobre padrões microbiológicos para alimentos. In: ANVISA (Agência Nacional de Vigilância Sanitária). [internet]. 2001. [acesso em 2017 Ago. 15]. DOI: http://bvsms.saude.gov.br/bvs/saudelegis/anvisa /2001/res0012 0201 2001.html

12. Legnani PP, Leoni E. Effect of processing and storage conditions on the microbiological quality of minimally processed vegetables. Int J Food Sci Technol. 2004;39:1061-8. DOI:

http://dx.doi.org/10.1111/i.1365-

\subsubsection{1.x}

13. Santos CMG, Braga $C$ de L, Vieira MR da $S$, Cerqueira RC, Brauer RL, Lima GPP. Qualidade da alface comercializada no município de botucatu SP. Rev Iber Tecnologia Postosecha. 2010;11(1):67-74.

14. Prado $S$ de $P T$, Ribeiro EGA, Capuano DM, Aquino AL de, Rocha $G$ de $M$, Bergamini AMM. Avaliação microbiológica, parasitológica e da rotulagem de hortaliças minimamente processadas comercializadas no município de Ribeirão Preto - SP/Brasil. Rev Inst Adolfo Lutz. 2013;67(3):221-7.

Recebido para publicação em 30/01/2017

Revisado em 30/08/2017

Aceito em 17/01/2018 